\title{
Clinical significance of long-term psychoanalytic treatment
}

\author{
Caspar C. Berghout, MA, and Jolien Zevalkink, PhD
}

The present study evaluated the clinical significance of long-term psychoanalytic treatment in four groups of about 60 patients in different phases of treatment (before, during, after, follow-up) with normative comparisons on four symptom questionnaires (SCL-90, BDI-II, STAI, IIP-64) and two personality assessment instruments (MMPI-2, Rorschach-CS). In each group, the proportion of patients with clinically elevated scores was calculated by comparing their scores with clinical and nonclinical reference groups for each instrument. The authors also calculated a combined percentage of clinically elevated scores based on the six instruments as a conservative estimate of improvement to nonclinical levels after long-term psychoanalytic treatment. Compared to pretreatment levels, the authors found a significant decrease in the percentage of clinical cases after treatment. For the personality assessment, these results became even more evident at follow-up. It appears that long-term psychoanalytic treatment was clinically significant for patients with chronic mental disorders. In the discussion, the authors point out that the evaluation of clinical significance at group level should be followed by an examination of individual changes over a longer period of time. (Bulletin of the Menninger Clinic, 73[1], 7-33)

Nowadays, psychotherapy outcome research does not focus solely on the statistical significance of treatment effects, but also on the clinical significance of the results by comparing test scores to normative samples. Normative comparisons provide evidence for

\footnotetext{
The authors gratefully acknowledge A.N.J. Pieters, Z. Saltzherr, and A. Beekhuyzen for coding the Rorschach protocols. This project was supported by the Netherlands ZonMw Grant 945-04-414.

Correspondence concerning this article should be addressed to C.C. Berghout, Department of Research and Quality Assurance, Netherlands Psychoanalytic Institute, PO Box 7031, 1007 JA Amsterdam, The Netherlands; e-mail: berghout@npsai.nl. (Copyright $($ C 2009 The Menninger Foundation)
} 
the clinical significance of therapeutic interventions (Kendall \& Grove, 1988; Kendall \& Norton-Ford, 1982). This approach differs from studying treatment outcome using traditional pre- versus post-treatment group mean comparisons in the sense that normative comparisons focus on whether or not the end-state functioning falls within the normative range on relevant outcome measures (Jacobsen, Follette, \& Revenstorf, 1984; Kendall, Marrs-Garcia, Nath, \& Sheldrick, 1999). This way, one can determine whether or not the therapeutic change has made a practical, beneficial impact on the patient's life. The assessment of clinical significance represents an important step forward in the evaluation of treatment effects (Kazdin, 1999).

For patients, therapists, and researchers, returning to normal functioning is probably one of the most important aspects of treatment outcome. There are numerous ways to assess clinical significance (e.g., Atkins, Bedics, McGlinchey, \& Beauchaine, 2005; Bauer, Lambert, \& Nielsen, 2004; Jacobsen, Roberts, Berns, \& McGlinchey, 1999; Ogles, Lunnen, \& Bonesteel, 2001; Wise, 2004). Outcome studies that assess clinical significance can focus on whether on not test scores of a person fall below or above a certain threshold (usually referred to as normative comparisons), and/or focus on the actual amount of change (usually referred to as reliable change; Jacobsen \& Truax, 1991). In this cross-sectional multicohort study, we used the first method to assess the clinical significance of long-term psychoanalytic treatment.

Normative comparisons tell us how the patient's level of functioning after treatment relates to that of the "functional" population and/or the "dysfunctional" population (Jacobsen et al., 1984; Jacobson \& Truax, 1991; Kendall et al., 1999). Assessing reliable change is not possible in a cross-sectional study due to a lack of outcome data on changes within individuals on all instruments. The main research question was whether long-term psychoanalytic treatment is effective in returning patients to normal functioning and reducing the number of clinical cases by comparing outcomes with data from normative samples.

Evaluating the clinical significance of two forms of long-term psychoanalytic treatment (psychoanalysis and psychoanalytic psychotherapy) is particularly interesting because of the high intensity of the clinical input provided. In several countries (e.g., Norway, 
Clinical significance of psychoanalytic treatment

Belgium, Germany, Canada, the Netherlands), governments still provide funding for these two forms of treatment, although research into its effectiveness has only recently become more substantial. Recent meta-analyses point out that psychoanalytic treatment has proven to be an effective treatment for depression (Leichsenring, 2001) and personality disorders (Leichsenring \& Leibing, 2003). Previous results from regular clinical practice had already shown that $91 \%$ of the patients presented substantial psychopathology, with especially high levels of depressive problems and (anxious) personality pathology at onset of long-term psychoanalytic treatment (Berghout \& Zevalkink, 2008).

This was in line with findings from other studies. Patients at onset of psychoanalytic treatment were found to score significantly higher on general symptomatology (SCL-90-R), depression (BDIII), anxiety (STAI), and interpersonal problems (IIP-64) compared to nonclinical norm groups, although not all patients had clinically elevated scores on all instruments (Finland: Knekt \& Lindfors, 2004; Germany: Brockmann, Schlüter, Brodbeck, \& Eckert, 2002; Leichsenring, Biskup, Kreische, \& Staats, 2005; Pushner, Kraft, \& Bauer, 2004; Sweden: Blomberg, Lazar, \& Sandell, 2001; Sandell et al., 2000; US: Vaughan et al., 2000). The next question we asked ourselves was whether or not psychoanalytic treatment can reduce this high number of clinical cases.

From the literature, we learned that several research studies reported on improvement rates and reduction in percentage of clinical cases. An early review by Bachrach, Galatzer-Levy, Skolnikoff, and Waldron (1991) found improvement rates between 60\% and $90 \%$ in returning patients to normal functioning as reported by clinicians. More recently, Leichsenring et al. (2005) reported that about $80 \%$ of the patients in psychoanalysis showed clinically significant improvements on symptomatic functioning at the end of treatment and at a 1-year follow-up. Sandell et al. (2000) assessed the proportion of patients that could be identified as "clinical cases" on the basis of three outcome measures in different phases of psychoanalysis and psychoanalytic psychotherapy. For psychoanalysis, $88 \%$ of their patients were clinical cases before treatment, with a substantial reduction to $33 \%$ clinical cases 3 years after treatment 
termination as measured with a composite measure consisting of SCL-90, SAS, and SOCS.

In the psychoanalytic psychotherapy group, there was a more modest decrease in the percentage of clinical cases, from $67 \%$ before treatment to $45 \%$ three years after treatment termination (Sandell et al., 2000). Grande et al. (2006) also studied the clinical significance of psychoanalysis and psychoanalytic psychotherapy and found significant results after treatment. For general psychopathology (SCL-90-R GSI), they found that $61 \%$ of the patients in psychoanalysis and $37 \%$ of the patients in psychoanalytic psychotherapy had posttreatment scores within the nonclinical range. With regard to the level of interpersonal problems (IIP-64 total score), $47 \%$ of the patients in psychoanalysis and $27 \%$ of the patients in psychoanalytic psychotherapy were at nonclinical levels after treatment. At follow-up, results were in the same direction, but no longer statistically significant (Grande et al., 2006). On the basis of these previous findings, we also expected to find a significant reduction in the number of patients with clinically elevated scores after psychoanalytic treatment as compared to our pretreatment group, and in particular better results for psychoanalysis than for psychoanalytic psychotherapy.

We examined the clinical effectiveness of long-term psychoanalytic treatment by investigating the proportion of patients with clinically elevated scores on four symptom measures and two personality assessment instruments in different phases of treatment. Because of the diversity and complexity of patients' problems, it is sensible to use multiple outcome measures for evaluating the clinical significance of treatment (Hill \& Lambert, 2004). The six instruments assess different areas of functioning and thus provide a broad perspective on therapy outcome (Kendall et al., 1999). Normative data of functional and dysfunctional populations were available for these instruments and were usually reported in the test manuals of the outcome measures. These data provide reliable estimates of general and/or clinical population parameters.

First, scores on the symptom measures and personality assessment instruments were analyzed separately. After that we calculated a combined index, which provided a conservative estimate of improvement after long-term psychoanalytic treatment based on the six instruments taken together. In the assessment of clinical 
Clinical significance of psychoanalytic treatment

cases, we followed other researchers who had shown that it is possible to use statistically defined cutoff values and combine different instruments to come to a global assessment of the percentage of clinical cases in a certain patient population (Blomberg et al., 2001; Puschner, Kraft, Kächele, \& Kordy, 2007; Rudd et al., 1996; Sandell et al., 2000).

Method

\section{Subjects}

The total sample consisted of 231 subjects from four mental health care organizations (Nederlands Psychoanalytisch Instituut, De Gelderse Roos, Mediant, Parnassia/Psy-Q). The majority of our sample $(73 \%)$ were women. The age range of our subjects ranged from 19 to 68 years, with an average age of 36 years $(S D=8.4)$. We found that $77 \%$ of all subjects had received previous (psycho-) therapeutic treatment before applying for long-term psychoanalytic treatment. Further, we found that $44 \%$ of the subjects were living with a partner, $21 \%$ had children, $92 \%$ had a Western cultural background, $76 \%$ had received higher education, and $79 \%$ was unemployed. Most frequently diagnosed DSM-IV Axis I disorders were mood disorders (47\%), particularly dysthymic disorder $(30 \%)$. With regard to Axis II diagnoses, we found that the majority of the patients $(73 \%)$ were diagnosed with a personality disorder.

In this study, we used a cross-sectional design with four different cohorts. These cohorts were representative samples of patients from different phases of treatment. The subjects were not randomly assigned to the cohorts or treatments but followed a naturalistic route through the clinical setting. This ensures high external validity and generalizabilty of the findings (Leichsenring, 2004; Seligman, 1995; for a more extensive description of the methodology, cf. Zevalkink \& Berghout, 2006). The advantage of such a research design is that we can obtain information about the effects of long-term treatments within a relatively short period of time (de Maat, Dekker, Schoevers, \& de Jonghe, 2007; Sandell, Blomberg, \& Lazar, 1997). By investigating the necessary information on 
patient characteristics and controlling for potential pretreatment differences, we intended to make the four cohorts as equivalent as possible regarding baseline characteristics (Bickman \& Rog, 1998). The pretreatment cohort $(n=64)$ consisted of patients who had just started long-term psychoanalytic treatment; in the duringtreatment cohort $(n=49)$ patients were 1 year into treatment; the end-of-treatment cohort $(n=67)$ consisted of persons who had just finished (approximately 3 months after treatment termination) long-term psychoanalytic treatment; and persons in the follow-up cohort $(n=51)$ had already finished their treatment 2 years ago.

Inclusion criteria for participation were a minimum age of 18 years, having mastery of the Dutch language, and assignment for long-term psychoanalytic treatment $(>25$ sessions or $>1$ year, with a minimum frequency of once a week). Exclusion criteria were the presence of (acute) psychotic symptoms. In each cohort, about $40 \%$ of the patients received psychoanalysis (PA) and $60 \%$ received psychoanalytic psychotherapy (PP). There were no significant differences across cohorts regarding the PA/PP distribution. Chi-square analyses and ANOVAs revealed no significant differences between the four cohorts on pretreatment (sociodemographic) patient characteristics (sex, treatment history, living situation, cultural background, educational level, source of income, DSM-IV Axis I diagnosis), except for age at intake and DSM-IV Axis II diagnosis. Subjects in the end-of-treatment cohort appeared to be somewhat younger at the start of treatment compared to subjects in the other cohorts ( $F=3.68, p<.05$, maximum difference of 3.2 years). The frequencies of Axis II diagnoses were roughly comparable across the four cohorts; however, in the pretreatment and during-treatment cohorts, there were significantly more patients with a personality disorder diagnosis at the start of treatment compared to the other two cohorts $\left(\chi^{2}=16.86, p<.01\right)$.

\section{Treatments}

Both psychoanalytic psychotherapy and psychoanalysis are openended long-term psychotherapeutic treatments, defined as consisting of 25 sessions or more and lasting more than 1 year. These psychoanalytic treatments have been described in textbooks (e.g., Etchegoyen, 1991; Greenson, 1967; Luborsky, 1984; Mitchell \& 
Clinical significance of psychoanalytic treatment

Black, 1995; Pine, 1990, 1998; Wallerstein, 1995). Efforts have been made to manualize psychoanalytic treatment, but so far this work has been complicated by the relative long duration of the treatment and the complexity of the technique. In general, psychoanalytic treatments share some common theoretical assumptions and intend to influence the working of unconscious processes by either focusing on conflicts, object relations, the self, and/or interactional processes (Gabbard, 2005; de Wolf, 2002). Psychoanalysis differs from psychoanalytic psychotherapy in that patients in psychoanalysis receive three or more sessions per week lying on the couch, while patients in psychoanalytic psychotherapy sit faceto-face and the frequency typically is one or two times a week. The average length of treatment was 6.5 years for PA $(S D=2.7$ yrs. $)$ and 3.9 years for PP $(S D=2.5 \mathrm{yrs}$.). As could be expected, this difference in treatment duration was significant $(F=29.0, p<.001)$. All therapists $(N=94)$ in the project are licensed clinicians (psychiatrists/ psychotherapists or psychologists/psychotherapists) and members of one of the Netherlands psychoanalytic societies.

\section{Measures}

In line with methodological recommendations, we used multiple outcome measures and data collection methods to enhance validity (Bickman \& Rog, 1998). For this project, four symptom measures (SCL-90-R, BDI-II, STAI, IIP-64) and two personality instruments (MMPI-2 and Rorschach-CS) were selected.

Symptom measures. The SCL-90-R measures symptoms in nine major areas of the patient's psychological, somatic, and interpersonal functioning. The 90 items are scored on a 5-point Likert scale (Derogatis, 1983). In the Netherlands, norms and translations were developed by Arrindell and Ettema (2003). The 21-item BDI-II measures depressive symptoms, scored on a 4-point Likert scale (Beck, Steer, \& Brown, 1996). In the Netherlands, van der Does (2002) translated the BDI-II and developed norm scores. The 40-item STAI assesses state and trait anxiety, scored on a 4-point Likert scale (Spielberger, 1983). State anxiety reflects a momentary anxiety, and trait anxiety refers to a general tendency to respond with anxiety to perceived threats in the environment. The STAI was published in the Netherlands and norm scores were developed 
by van der Ploeg (2000). The IIP consists of 64 items, scored on a 5 -point Likert scale, that assess perceived interpersonal difficulties on eight subscales (Horowitz, Alden, Wiggins, \& Pincus, 2000). Clinical norm scores were derived from Horowitz, Strauss, and Kordy (1994). For each of the questionnaires we used only the total or overall sum scores.

Personality assessment. The MMPI-2 (Butcher, Dahlstrom, Graham, Tellegen \& Kaemmer, 1989), a 567-item self-report questionnaire, aims to quantitatively measure an individual's level of emotional adjustment and attitude toward test taking, resulting in clusters of personality variables (Groth-Marnat, 1997). In concordance with other research on the MMPI-2, we did not use scale 5-Masculinity-Femininity (Mf), because this scale is usually not considered as a clinical scale that measures psychopathology (e.g., Nieberding et al., 2003; Terlidou et al., 2004). Derksen, de Mey, Sloore, and Hellenbosch (2006) translated the MMPI-2 and developed norms for use in the Netherlands.

The Rorschach inkblot test measures different dimensions of personality functioning and has been used as a diagnostic tool and outcome instrument in psychoanalytic treatment for quite some time (e.g., Ganellen, 1996; Grønnerød, 2004; Viglione, 1999). It assesses clients' personality structure, with particular emphasis on understanding how they respond to and organize their environment. In this way, it can also be considered a measure of perception and association (Weiner, 1998). It consists of a set of 10 bilaterally symmetrical inkblots on sturdy cards. Three psychologists with extensive training and experience in the Comprehensive System (CS) scored the Rorschach (Exner, 2001, 2003). A number of variables were selected that were found to be important in assessing differences as a result of psychotherapeutic treatment.

We selected eight variables of the CS (the six Special Indices, EII-2, AdjD) because those are assumed to be global measures of personality functioning. Based on age and sex-differentiated norms of clinical and nonclinical reference groups, the CS produces aggregate scores on six Special Indices: Perceptual-Thinking (PTI), Depression (DEPI), Coping Deficit (CDI), Suicide Constellation (SCON), Hypervigilance (HVI), and Obsessive Style (OBS). The Ego Impairment Index (EII-2) is a relatively new Rorschach composite and measures psychological impairment and thought disturbance 
Clinical significance of psychoanalytic treatment

(Viglione, Perry, \& Meyer, 2003). The Adjusted D score (AdjD) score gives an indication of whether a person typically has adequate resources to manage problems. Norm scores for the Rorschach-CS were derived from Exner (2001).

\section{Procedure}

All patients who met the inclusion criteria were approached via mail. An informed consent with a return envelope was enclosed in the letter as well. In total we approached 383 persons to participate, of which 247 (65\%) persons said "Yes," 81 (21\%) said "No," and $55(14 \%)$ never responded. Of the 247 persons who agreed to participate, 16 eventually did not participate in the study for varying reasons (e.g., withdrawal from the study, never started the psychoanalytic treatment). Chi-square analyses and ANOVAs showed that these 16 dropouts did not differ significantly $(p<.05)$ on pretreatment sociodemographic and diagnostic characteristics from the 231 subjects who actually did participate. When subjects returned a positive informed consent, we telephoned them to make an appointment for the personality assessment (MMPI-2 and Rorschach-CS). At that time, we also sent them the symptom questionnaires by regular mail. They could send these questionnaires back in a stamped envelope. Data gathering was done between January 2004 and June 2007. The personality assessments were done by researchers, psychologists, clinicians and research assistants trained in administering the Rorschach.

\section{Data analyses}

We investigated the raw Rorschach data and evaluated whether the Rorschach protocols in all four cohorts were equally complex. After computing $\mathrm{z}$-scores for $\mathrm{R}$ (number of responses) and Form \% (measure of defensiveness), we computed a summary index of complexity by calculating the average z-scores after reversing the direction of the Form\% variable. We found no significant differences in $\mathrm{R}$, Form \%, and response complexity. The values indicate that overall we are dealing with high R-low Lambda patients, that is, persons who give rich and elaborate responses. In line with Meyer (1992, 1993), we corrected for the influence of $\mathrm{R}$ (number of responses) on the raw scores by dividing all raw scores by $\mathrm{R}$ and 
multiplying by 20.25 . The multiplier is the average $\mathrm{R}$ in the adult outpatient norm group (Exner, 2001). With raw scores no longer confounded by variations in $\mathrm{R}$, structural data would be easier to interpret and more suitable for research purposes (Meyer, 1992, 1993). Missing values $(4.8 \%)$ were replaced by the mean group average of the corresponding cohort.

Next, we calculated the percentages of patients who scored above (or below) a certain cutoff on the different assessment instruments. One of the most often used, and perhaps the least arbitrary, is a cutoff based on information from both functional and dysfunctional populations (cutoff $\mathrm{C}$ ) that allows precise determination of which population a subject's score belongs in (Jacobsen et al., 1984; Jacobsen \& Truax, 1991). According to this definition, a clinically elevated score is defined as a score that is closer to the mean of the clinical population than to the nonclinical population. The formula for the calculation of this cutoff value is as follows:

$$
\text { Cutoff }=\frac{\left(S D_{0} \times M_{1}\right)+\left(S D_{1} \times M_{0}\right)}{\left(S D_{0}+S D_{1}\right)}
$$

where

$M_{0}=$ mean score in the nonclinical reference group,

$S D_{0}=$ standard deviation in the nonclinical reference group,

$M_{1}=$ mean score in the clinical reference group, and

$S D_{1}=$ standard deviation in the clinical reference group.

The cutoff values of the four symptom measures and the MMPI-2 scales are shown in Table 1. In the following, we have reported the chi-square analyses of the differences between the pretreatment cohort and the end-of-treatment cohort as well as those between the pretreatment cohort and the follow-up cohort. Raw percentage data are reported for all cohorts. Chi-square analyses revealed no significant differences between the pretreatment cohort and the during-treatment cohort in the number of patients with clinically elevated scores on both the symptom measures and the two personality measures. Therefore, the next results will only show proportions for the during-treatment cohort in the tables. Chi-square analyses revealed no significant differences between PA and PP patients on initial impairment or treatment outcome. Therefore, we 
Clinical significance of psychoanalytic treatment

report the aggregated results from both patient groups together as one large group.

Results

\section{Symptom measures}

Table 2 shows the percentages of patients with clinically elevated scores on the symptom measures in the different phases of treatment. Chi-square analyses revealed significant differences on all four questionnaires between the pretreatment group and the endof-treatment and follow-up groups in number of patients with clinically elevated scores.

\section{Personality assessment}

Table 3 shows the percentages of patients with clinically elevated scores on the MMPI- 2 clinical scales in the different phases of treatment. The results show significant decreases in the percentage of patients with clinically elevated scores on several MMPI-2 clinical scales, but not on all scales. Pretreatment versus end-of-treatment comparisons revealed significant differences in the number of patients with elevated scores on the scales for Depression, Hysteria, Psychopathic Deviate, Psychasthenia, and Social Inhibition. And with our pretreatment versus follow-up comparisons we found significant effects on the scales for Depression, Psychopathic Deviate, and Psychasthenia.

Table 4 shows the percentages of patients with clinically elevated scores on the Rorschach scales in the different phases of treatment. We found a significant decrease in the percentage of patients with an elevated score on the Perceptual Thinking Index (PTI). On the other Rorschach scales, we did not find significant decreases in the proportion of patients with clinically elevated scores. Secondary analyses on the potential differential effect of treatment type revealed that the decrease in clinically elevated scores on the PTI was mainly due to patients in psychoanalysis. Post-hoc chi-square analyses revealed significant differences in the number of clinically elevated scores on the PTI between pretreatment and end-oftreatment $\left(24 \%\right.$ vs. $\left.3 \%, \chi^{2}=5.46, p<.05\right)$ and a statistical trend between pretreatment and follow-up $\left(24 \%\right.$ vs. $5 \%, \chi^{2}=3.49, p$ 
Berghout and Zevalkink
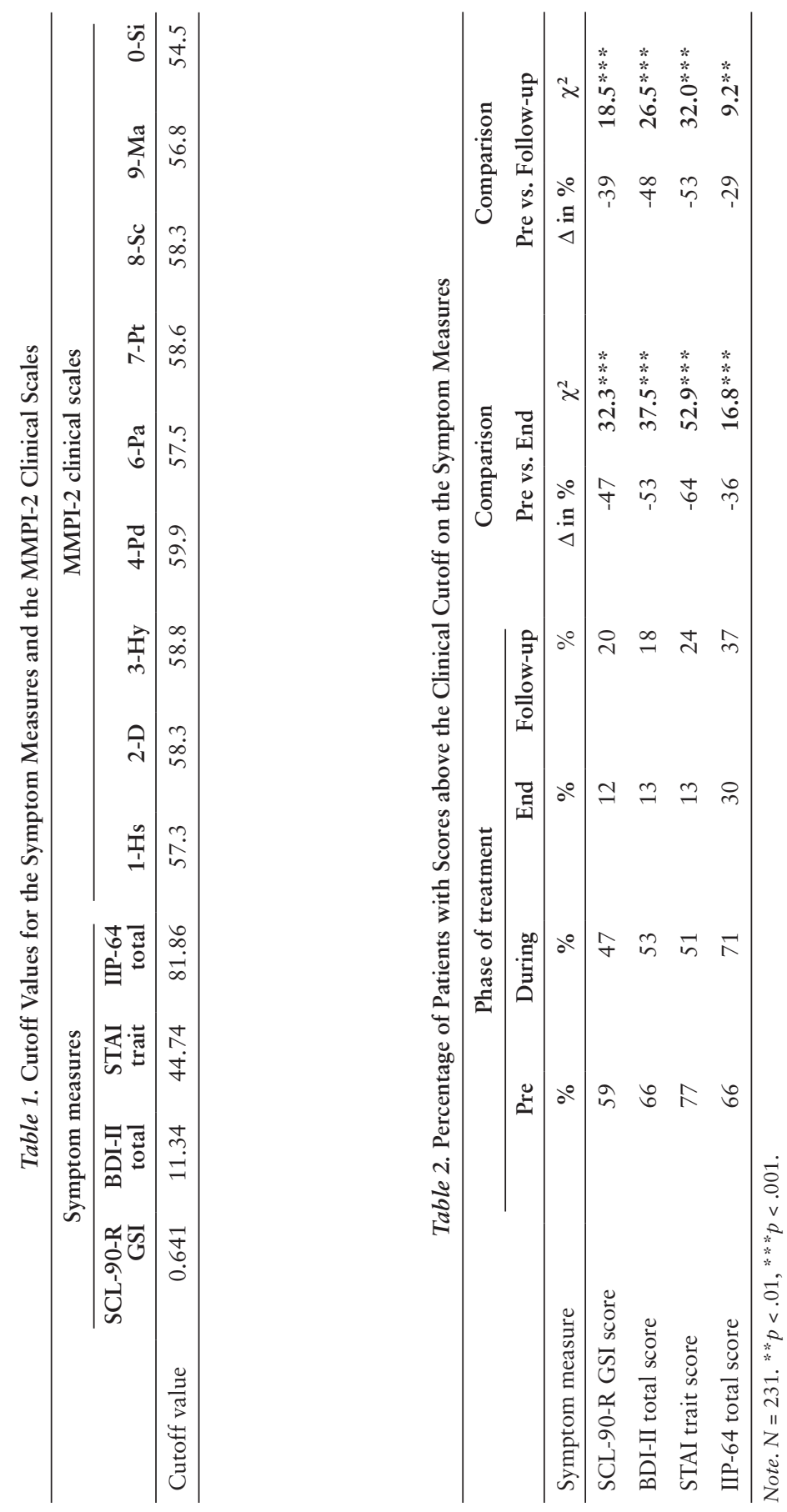
Clinical significance of psychoanalytic treatment

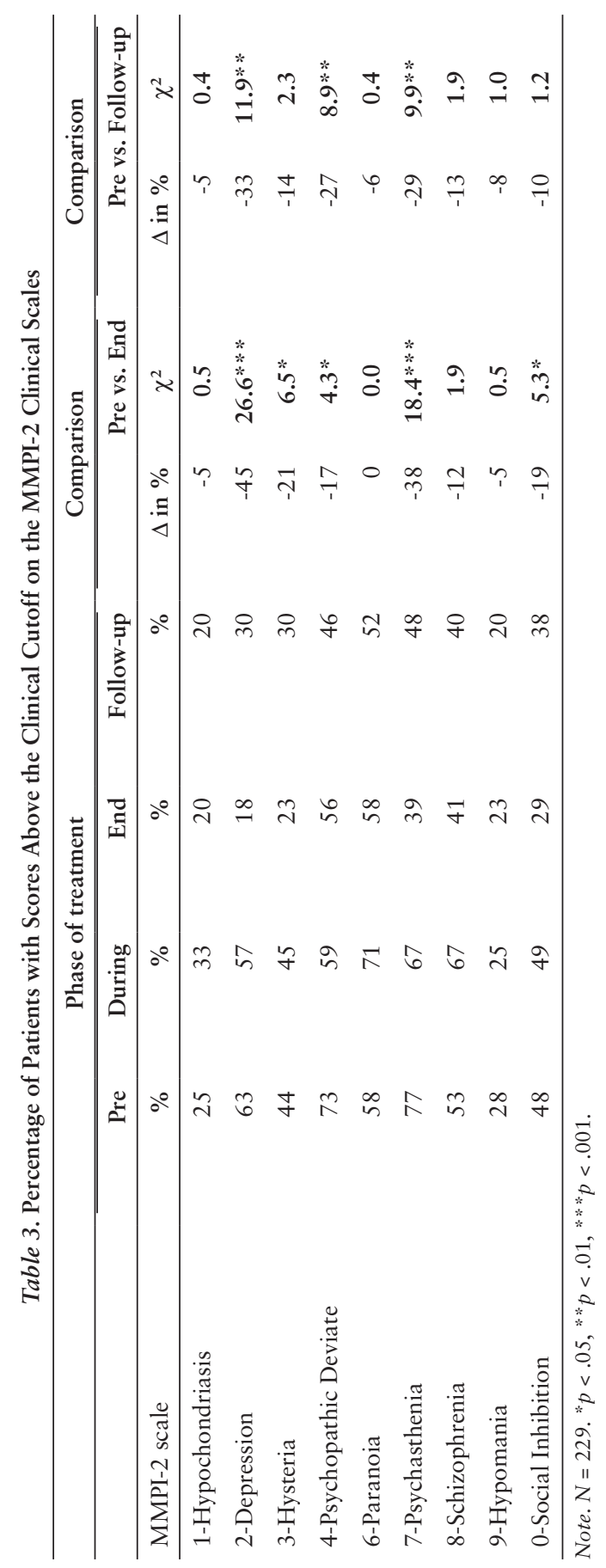

Vol. 73, No. 1 (Winter 2009) 
Berghout and Zevalkink

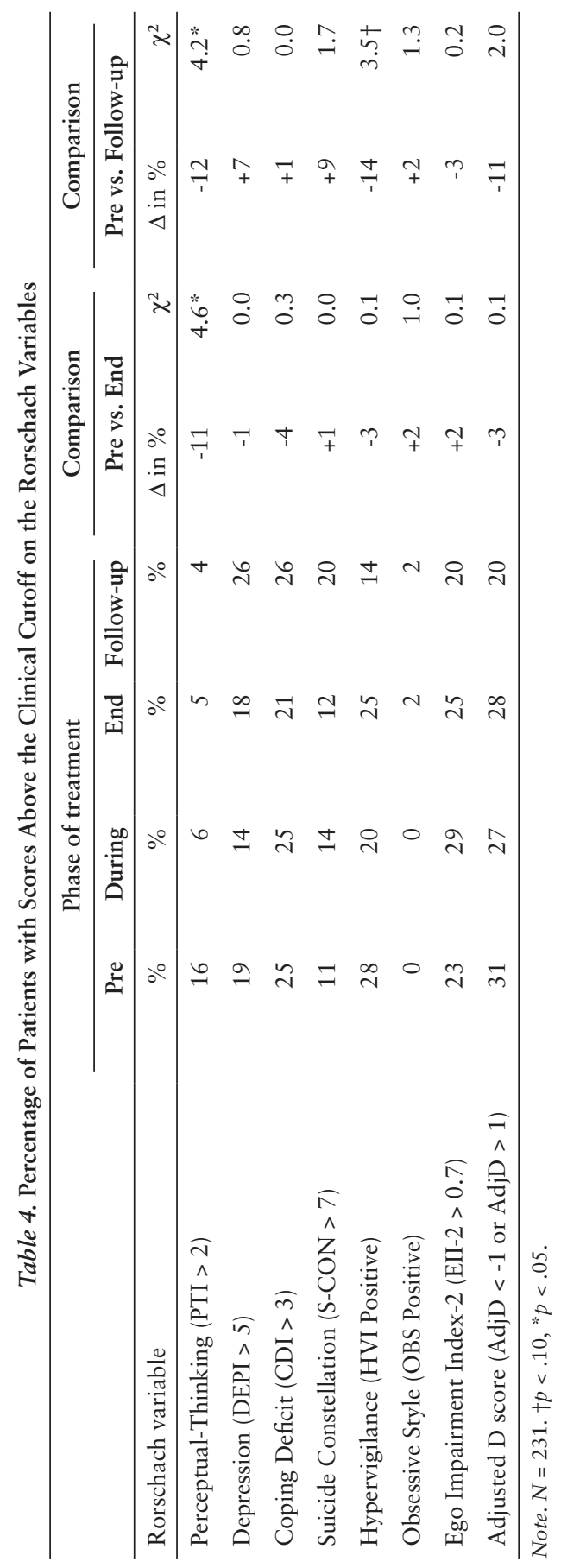


Clinical significance of psychoanalytic treatment

$<.10)$ in the PA-group, but no significant differences between the cohorts in the PP group.

\section{Combining instruments: Clinical cases across instruments}

After investigating the percentage of clinical cases for each instrument separately, we combined the test scores from the four symptom measures and calculated the percentages of patients who scored within the clinical range on at least two symptom measures. In comparison to the pretreatment cohort, results showed a significant reduction in the number of patients with clinically elevated scores on at least two symptom measures at the end of treatment $(75 \%$ vs. $18 \%)$ and at follow-up $(75 \%$ vs. $26 \%)$ (see Table 5 ). With regard to the MMPI-2, we found a significant reduction in the number of patients who had clinically elevated scores on at least two MMPI-2 clinical scales at treatment termination and at follow-up. On the Rorschach-CS, we found a significant reduction in the percentage of patients with at least two clinically elevated Rorschach indices at follow-up but not at the end of treatment.

Finally, we combined the results from the symptom measures with the personality assessment instruments and we redefined a clinical case as someone who fulfilled at least two of the three following criteria: (1) clinically elevated scores on at least two symptom measures; (2) clinically elevated scores on at least two MMPI-2 clinical scales; and (3) clinically elevated scores on at least two Rorschach indices. Based on this definition, a significant reduction in the percentage of clinical cases after psychoanalytic treatment was found both after treatment ( $84 \%$ vs. $41 \%)$ and at follow-up $(84 \%$ vs. $40 \%$ ) compared to the percentage of patients before treatment. The still relatively high number of clinical cases after treatment was mainly due to the results of the personality assessments.

Further, we performed exploratory analyses to identify the characteristics of the subjects with the most unfavorable treatment outcome. From the end-of-treatment and follow-up cohorts, we distinguished six subjects with clinically elevated scores on the symptom measures and on the MMPI-2 and on the Rorschach-CS. Sociodemographic characteristics of this small subgroup did not differ significantly from those with more favorable treatment outcome. Examination of pretreatment DSM-IV diagnoses did show that all 
Berghout and Zevalkink

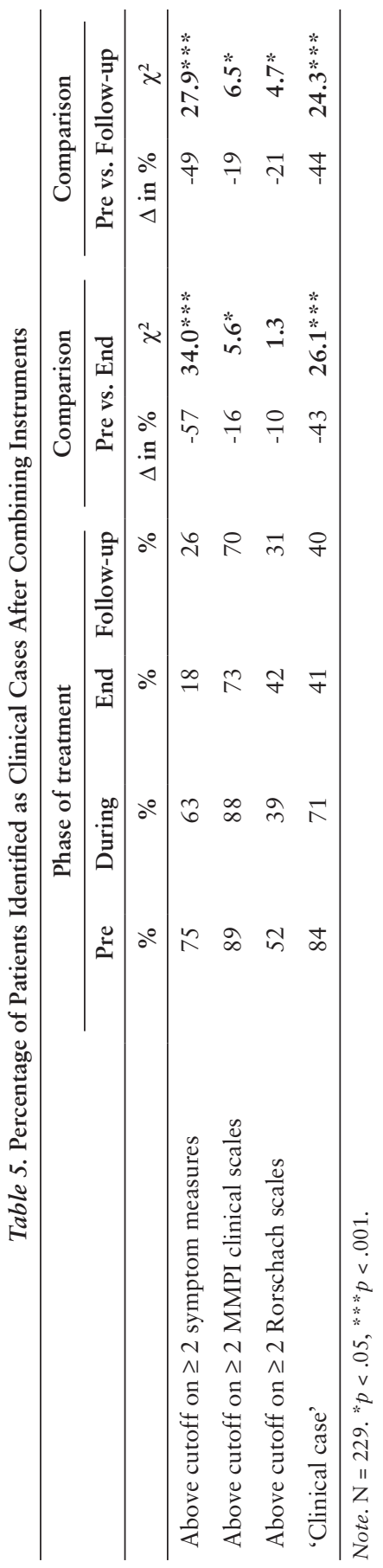


Clinical significance of psychoanalytic treatment

six subjects $(100 \%)$ were diagnosed with a personality disorder at the start of treatment, whereas $60 \%$ of the patients with a more favorable treatment outcome were diagnosed with a personality disorder at the start of treatment $\left(\chi^{2}=3.84, p<.10\right)$.

\section{Discussion}

In this study, we investigated the clinical significance of long-term psychoanalytic treatment by examining the percentage of patients considered to function normally (i.e., at nonclinical levels) in different phases of treatment. The vast majority of patients were identified as clinical cases before treatment on the basis of six instruments measuring both symptoms and personality functioning. After treatment, we found a significant decrease in the number of clinical cases, and these results became even more evident at follow-up for the personality assessment. The results of these normative comparisons signify clinically meaningful improvements in real life.

In particular, our results showed large reductions in the number of patients with clinically elevated scores on the symptom measures, but also significant improvements on the personality measures. These results are in line with other studies on the clinical significance of psychoanalytic treatment (Grande et al., 2006; Leichsenring et al., 2005; Perry, Banon, \& Ianni, 1999; Sandell et al., 2000). Thus far, the evaluation of clinical significance in treatment outcome research has mainly emphasized symptom reduction (Kazdin, 1999). The current study can be considered a valuable addition to the literature because of the comprehensive personality assessment of each patient.

The long-term effects of psychoanalytic treatment were particularly apparent on the MMPI-2 scales for Depression, Psychopathic Deviate, and Psychasthenia. This means that the presence and depth of depression, the level of social maladjustment and feelings of alienation, and the level of (social) anxiety and self-doubt were all substantially reduced after long-term psychoanalytic treatment. Furthermore, at 2-year follow-up, we still found significant differences with the pretreatment group on these personality variables.

Apparently long-term psychoanalytic treatment is especially effective in returning patients to normal functioning in these areas 
and sustaining these improvements over a longer period of time. These variables appear to play an important role in treatment monitoring, in the sense that improvements in these areas could be expected after being in psychoanalytic treatment. The other MMPI-2 variables appear to be more stable and therefore less suitable to monitor change in psychoanalytic treatment.

Overall, we found substantial decreases in the number of patients with clinically elevated scores on all instruments, but the effects on the Rorschach-CS were the smallest. Perhaps this is because the global indices of the Rorschach-CS give us an estimation of our most stable personality traits, and on this level of functioning one would obviously expect the least changes. On an idiosyncratic lev$\mathrm{el}$, the Rorschach-CS is an invaluable instrument to identify someone's strong as well as weak points and use this information for thorough clinical decision making before treatment.

Although several studies have shown that the Rorschach-CS can also be a valuable instrument in monitoring treatment outcome (e.g., Ganellen, 1996; Grønnerød, 2004; Viglione, 1999; Weiner \& Exner, 1991), we found that using the global indices of the Rorschach-CS for measuring treatment outcome when comparing groups of patients appeared to be less useful. However, the combined score showed a significant decrease in clinical cases-as measured with the Rorschach-at 2-year follow-up. This might also be interpreted as a postponed sleeper effect of the psychoanalytic treatment on structural personality aspects, such as reduction of distrust in others (HVI) and better reality testing (PTI).

Although we found encouraging results about the clinical significance of psychoanalytic treatment effects, there was still a sizable proportion of patients with clinically elevated scores on our assessment instruments after treatment. For instance, $18 \%$ of the patients still had clinically elevated scores on the MMPI-2 Depression scale at the end of treatment, for the BDI-II this percentage was $13 \%$; and on the Depression scale of the Rorschach-CS this percentage was $18 \%$. These results are in line with findings from a review of psychotherapy for depression, which suggested that most treated patients did show progress but were still more depressed than normative samples (Robinson, Berman, \& Neimeyer, 1990). As Wise (2004) also pointed out, a complete return to normal functioning might not be realistic for intensive outpatient treatments. It 
Clinical significance of psychoanalytic treatment

could be that certain patients went through substantial change but at the end of treatment were still not functioning in the normative range.

In the literature, these cases are normally referred to as improved, in contrast to recovered (Jacobsen \& Truax, 1991). However, with our cross-sectional research design we were not able to examine these individual changes. Our exploratory analyses showed that the subjects with the most unfavorable treatment outcome were all diagnosed with a personality disorder at the start of treatment, while in the subgroup of patients with a more favorable treatment outcome, $60 \%$ were diagnosed with a personality disorder at the start of treatment. This could mean that the presence of a personality disorder can have a detrimental effect on treatment outcome; however, it does not necessarily mean that all patients with a personality disorder will have an unfavorable treatment outcome.

In the research literature there is a growing body of evidence that patients with a personality disorder have worse treatment outcome compared to those without a personality disorder (e.g., Diguer, Barber, \& Luborsky, 1993; Newton-Howes, Tyrer, \& Johnson, 2006; Reich, 2003; Shea, Widiger, \& Klein, 1992). Our exploratory findings are in line with these results, but further research is needed to identify exactly which patient/therapist/treatment characteristics are reliable predictors of an unfavorable treatment outcome, so that the treatment may be contraindicated in the future for certain subgroups or subtypes of patients.

Another noteworthy finding was that the number of clinical cases after 1 year of treatment was comparable to that before treatment. In contrast to often found symptom decreases within the first year of (short-term) psychotherapy (Howard, Kopta, Krause, \& Orlinsky, 1986; Kopta, Howard, Lowry, \& Beutler, 1994), the current study shows that in this particular patient population the level of symptoms and personality problems does not decrease rapidly, justifying a longer treatment process. Moreover, we found that $77 \%$ of the patients had already tried a previous (short-term) treatment, which strengthens our belief that we are dealing with a patient population with chronic symptoms/problems that are perhaps more resistant to change and require a more intensive form of therapy, such as long-term psychoanalytic treatment. It appears 
that patients in psychoanalytic treatment follow a different (and slower) pattern of change compared to those in short-term therapies, which are primarily focused on symptom reduction. This hypothesis could be further investigated by performing growth curve analyses to study the exact trajectories of symptoms and personality functioning in long-term psychoanalytic treatment.

The definition of clinical significance and the selection of instruments are crucial in this discussion. Because there is a lack of consensus regarding what measures are the most appropriate in assessing the clinical significance of treatment effects, it is recommended that multiple measures be used simultaneously. In this we followed other studies (Blomberg et al., 2001; Derogatis \& Lazarus, 1994; Puschner et al., 2007; Rudd et al., 1996; Sandell et al., 2000) and tried to make an even more conservative estimate of the number of clinical cases. Of course, clinical significance also depends on the goals of treatment and the nature of the problems of the patient population (Foster \& Mash, 1999; Kazdin, 1999). Because the goals of long-term psychoanalytic treatment are both structural and symptomatic change, we used personality assessment instruments as well as symptom questionnaires.

Another essential issue is the selection of normative data. Tingey, Lambert, Burlingame, and Hansen (1996) pointed out that although identifying normative reference groups is essential in evaluating clinical significance, here too there is a lack of consensus or guidelines for selecting these groups. As an addition to the clinical significance literature, they proposed a four-group distinction (asymptomatic, mildly symptomatic, moderately symptomatic, severely symptomatic) instead of a two-group (clinical and nonclinical) distinction for a more sensitive analysis of clinical significance. However, in practice, most measures only have established norms for a functional and a dysfunctional population and not for groups that are somewhere in between. Tingey et al. (1996) do touch on an important issue however, because the selection of the reference groups determines the cutoffs directly and therefore can significantly influence the results. So in this, we are dependent on the availability, quality, and representativeness of the reference groups that are mentioned in the manuals of the assessment instruments. For the MMPI-2, we used a clinical sample of outpatients patients with relatively mild distress. Consequently, the means of 
Clinical significance of psychoanalytic treatment

the MMPI-2 scales in the nonclinical and clinical norm groups were located fairly close to each other. This could perhaps explain why we still found a lot of clinically elevated scores on the MMPI-2 scales after treatment, because the cutoff values that distinguish between nonclinical and clinical were relatively low. More research is needed to evaluate alternative cutoff points and their utility in distinguishing between clinical and nonclinical groups.

In multiple-cohort designs a potential form of confounding involves differences in background characteristics and level of pretreatment psychopathology between the cohorts (Cogan \& Porcerelli, 2005). One cannot be sure that the patients enrolled in the various cohorts were exactly equivalent in terms of baseline psychopathology and background characteristics. It could be that patients with more psychopathology might be more apt to drop out of treatment and, in selecting subjects for the two posttreatment samples, we may have included more subjects who were relatively higher-functioning at the start of treatment compared to the other two cohorts. This could potentially influence the results of our cohort comparisons. In the present study, we compared the four cohorts on pretreatment DSM-IV-R diagnoses and sociodemographic characteristics. We found no significant differences on most variables, thus providing a strong check for the comparability of the four cohorts.

Another issue to keep in mind is that age and treatment effects could have occurred. Age effects are those associated with personal maturation that persons would presumably experience during any period of time (Raudenbush \& Chan, 1992). With regard to treatment effects, one could argue that it is impossible to know whether the improvements we found are actually attributable to the treatment given. It is not possible to draw causal inferences from the presented data. We have to be careful in drawing conclusions about the clinical significance of both treatments. A related issue is that in cross-sectional studies, ideas about changes within individuals cannot be tested. We are only able to talk about differences between patients on a group level and not of individual changes in patients over time. Therefore, we encourage further studies on the clinical significance of long-term psychoanalytic treatment effects that also investigate reliable changes on an individual level. 
Although the present study has certain limitations, we think the results of our study make a valuable contribution to the evidence about the clinical significance of long-term psychoanalytic treatments. The major merits of this study were the large sample size, the high external validity, and the comprehensive personality assessment. A large proportion of patients with chronic symptoms of depression and personality pathology appeared to profit from long-term psychoanalytic treatment. These effects were not yet visible after 1 year of treatment, but more so at the end of treatment and at 2-year follow-up. Psychoanalytic treatment has made a practical, beneficial, and clinically relevant impact on the patients' lives, given our findings that the presence and depth of depression, the clinical level of social maladjustment and feelings of alienation, and the clinical level of (social) anxiety and self-doubt were all substantially reduced after long-term psychoanalytic treatment.

\section{References}

Arrindell, W.A., \& Ettema, J.H.M. (2003). Symptom Checklist: Handleiding bij een multidimensionele psychopathologie-indicator [Symptom Checklist: Manual of the multidimensional indicator of psychopathology]. Lisse: Swets Test Publisher.

Atkins, D.C., Bedics, J.D., McGlinchey, J.B., \& Beauchaine, T.P. (2005). Assessing clinical significance: Does it matter which method we use? Journal of Consulting and Clinical Psychology, 73, 982-989.

Bachrach, H.M., Galatzer-Levy, R., Skolnikoff, A., \& Waldron Jr., S. (1991). On the efficacy of psychoanalysis. Journal of the American Psychoanalytic Association, 39, 871-916.

Bauer, S., Lambert, M.J., \& Nielsen, S.L. (2004). Clinical significance methods: A comparison of statistical techniques. Journal of Personality Assessment, 82, $60-70$.

Beck, A.T., Steer, R.A., \& Brown, G.K. (1996). Manual for Beck Depression Inventory-II. San Antonio, TX: Psychological Corporation.

Berghout, C.C., \& Zevalkink, J. (2008). Identifying clinical cases among patients assigned to psychoanalytic treatment. Bulletin of the Menninger Clinic, 72, 163-178.

Bickman, L., \& Rog, D.J. (1998). Handbook of applied social research methods. Thousand Oaks, CA: Sage Publications.

Blomberg, J., Lazar, A., \& Sandell, R. (2001). Long-term outcome of long-term psychoanalytically oriented therapies: First findings of the Stockholm Outcome of Psychotherapy and Psychoanalysis study. Psychotherapy Research, 11, 361-382. 
Brockmann, J., Schlüter, T., Brodbeck, D., \& Eckert, J. (2002). Die effekte psychoanalytisch orientierter und verhaltenstherapeutischer langzeittherapien [Effects of psychoanalytically oriented and behavioral long-term therapies]. Psychotherapeut, 47, 347-355.

Butcher, J.N., Dahlstrom, W.G., Graham, J.R., Tellegen, A., \& Kaemmer, B. (1989). The Minnesota Multiphasic Personality Inventory-2 (MMPR-2): Manual for administration and scoring. Minneapolis, MN: University of Minnesota Press.

Cogan, R., \& Porcerelli, J.H. (2005). Clinician reports of personality pathology of patients beginning and patients ending psychoanalysis. Psychology and Psychotherapy: Theory, Research and Practice, 78, 235-248.

Derksen, J.J.L., de Mey, H.R.A., Sloore, H., \& Hellenbosch, G. (2006). MMPI-2: Handleiding voor afname, scoring en interpretatie [MMPI-2: Manual for administration, scoring and interpretation]. Nijmegen: Pen Psychodiagnostics.

Derogatis, L.R. (1983). SCL-90-R: Administration, scoring and procedures manual II. Townson, MD: Clinical Psychometric Research.

Derogatis, L.R., \& Lazarus, L. (1994). SCL-90-R, Brief Symptom Inventory, and matching clinical rating scales. In M.E. Maruish (Ed.), The use of psychological testing for treatment planning and outcome assessment (pp. 217-248). Hillsdale, NJ: Lawrence Erlbaum.

Diguer, L., Barber, J.P., \& Luborsky, L. (1993). Three concomitants: Personality disorders, psychiatric severity, and outcome of dynamic psychotherapy of major depression. American Journal of Psychiatry, 150, 1246-1248.

Does, A.J.W. van der (2002). BDI-II-NL: Handleiding Beck Depression Inventory-II, Nederlandse vertaling en bewerking [BDI-II-NL: Manual Beck Depression Inventory-II, Dutch translation and adaptation]. Lisse: Swets Test Publisher.

Etchegoyen, R.H. (1991). Fundamentals of psychoanalytic technique. London/ New York: Karnac Books.

Exner, J.E. (2001). A Rorschach workbook for the Comprehensive System. Asheville, NC: Rorschach Workshops.

Exner, J.E. (2003). The Rorschach: A Comprehensive System (4th ed.). Hoboken, NJ: John Wiley \& Sons, Inc.

Foster, S.L., \& Mash, E.J. (1999). Assessing social validity in clinical treatment research issues and procedures. Journal of Consulting and Clinical Psychology, 67, 308-319.

Gabbard, G.O. (2005). Psychodynamic psychiatry in clinical practice. The DSMIV edition (3rd ed.). Washington, DC: American Psychiatric Press.

Ganellen, R.J. (1996). Comparing the diagnostic efficiency of the MMPI, MCMIII, and Rorschach: A review. Journal of Personality Assessment, 67, 219-243.

Grande, T., Dilg, R., Jakobsen, T., Keller, W., Krawietz, B., Langer, M., et al. (2006). Differential effects of two forms of psychoanalytic therapy: Results of the Heidelberg-Berlin study. Psychotherapy Research, 16, 470-485.

Greenson, R.R. (1967). The technique and practice of psychoanalysis. New York: International Universities Press.

Grønnerød, C. (2004). Rorschach assessment of changes following psychotherapy: A meta-analytic review. Journal of Personality Assessment, 83, 256-276. 
Groth-Marnat, G. (1997). Handbook of psychological assessment. Hoboken, NJ: John Wiley \& Sons.

Hill, C.E., \& Lambert, M.J. (2004). Methodological issues in studying psychotherapy processes and outcomes. In M.J. Lambert (Ed.), Bergin and Garfield's handbook of psychotherapy and behavior change (5th ed., pp. 84-135). New York: John Wiley \& Sons.

Horowitz, L., Strauss, B., \& Kordy, H. (1994). Das Inventar zur Erfassung interpersoneller Probleme (Deutsche Version) [Inventory of interpersonal problems (German version)]. Weinheim: Beltz Testverlag.

Horowitz, L.M., Alden, L.E., Wiggins, J.S., \& Pincus, A.L. (2000). Inventory of Interpersonal Problems: Manual. New York: The Psychological Corporation Harcourt.

Howard, K.I., Kopta, S.M., Krause, M.S., \& Orlinsky, D.E. (1986). The doseeffect relationship in psychotherapy. American Psychologist, 41, 159-164.

Jacobsen, N.S., Follette, W.C., \& Revenstorf, D. (1984). Psychotherapy outcome research: Methods for reporting variability and evaluating clinical significance. Behavior Therapy, 15, 336-352.

Jacobsen, N.S., Roberts, L.J., Berns, S.B., \& McGlinchey, J.B. (1999). Methods of defining and determining the clinical significance of treatment effects: Description, application, and alternatives. Journal of Consulting and Clinical Psychology, 67, 300-307.

Jacobsen, N.S., \& Truax, P. (1991). Clinical significance: A statistical approach to defining meaningful change in psychotherapy research. Journal of Consulting and Clinical Psychology, 59, 12-19.

Kazdin, A.E. (1999). The meanings and measurement of clinical significance. Journal of Consulting and Clinical Psychology, 67, 332-339.

Kendall, P.C., \& Grove, W.M. (1988). Normative comparisons in therapy outcome. Behavioral Assessment, 10, 147-158.

Kendall, P.C., Marrs-Garcia, A., Nath, S.R., \& Sheldrick, R.C. (1999). Normative comparisons for the evaluation of clinical significance. Journal of Consulting and Clinical Psychology, 67, 285-299.

Kendall, P.C., \& Norton-Ford, J.D. (1982). Therapy outcome research methods. In P.C. Kendall \& J.N. Butcher (Eds.), Handbook of research methods in clinical psychology (pp. 429-460). New York: Wiley.

Knekt, P., \& Lindfors, O. (2004). A randomized trial of the effect of four forms of psychotherapy on depressive and anxiety disorders: Design, methods, and results on the effectiveness of short-term psychodynamic psychotherapy and solution-focused therapy during a one-year follow-up. Helsinki: Edita.

Kopta, S.M., Howard, K.I., Lowry, J.L., \& Beutler, L.E. (1994). Patterns of symptomatic recovery in psychotherapy. Journal of Consulting and Clinical Psychology, 62, 1009-1016.

Leichsenring, F. (2001). Comparative effects of short-term psychodynamic therapy and cognitive-behavioral therapy in depression: A meta-analysis. Clinical Psychology Review, 21, 401-419.

Leichsenring, F. (2004). Randomized controlled versus naturalistic studies: A new research agenda. Bulletin of the Menninger Clinic, 68, 137-151. 
Leichsenring, F., Biskup, J., Kreische, R., \& Staats, H. (2005). The Göttingen study of psychoanalytic therapy: First results. International Journal of Psychoanalysis, 86, 433-455.

Leichsenring, F., \& Leibing, E. (2003). The effectiveness of psychodynamic therapy and cognitive behavior therapy in the treatment of personality disorders: A meta-analysis. American Journal of Psychiatry, 160, 1223-1232.

Luborsky, L. (1984). Principles of psychoanalytic psychotherapy. A manual for supportive-expressive treatment. New York: Basic Books.

Maat, S. de, Dekker, J., Schoevers, R., \& Jonghe, F. de (2007). The effectiveness of long-term psychotherapy: Methodological research issues. Psychotherapy Research, 17, 59-65.

Meyer, G.J. (1992). Response frequency problems in the Rorschach: Clinical and research implications with suggestions for the future. Journal of Personality Assessment, 58, 231-244.

Meyer, G.J. (1993). The impact of response frequency on the Rorschach constellation indices and on their validity with diagnostic and MMPI-2 criteria. Journal of Personality Assessment, 60, 153-180.

Mitchell, S.A., \& Black, M.J. (1995). Freud and beyond: A history of modern psychoanalytic thought. New York: Basic Books.

Newton-Howes, G., Tyrer, P., \& Johnson, T. (2006). Personality disorder and the outcome of depression: Meta-analysis of published studies. British Journal of Psychiatry, 188, 13-20.

Nieberding, R.J., Gacono, B.B., Pirie, M., Bannatyne, L.A., Viglione, D.J., Cooper, B., et al. (2003). MMPI-2 based classification of forensic psychiatric outpatients: An exploratory cluster analytic study. Journal of Clinical Psycho$\log y, 59,907-920$.

Ogles, B.M., Lunnen, K.M., \& Bonesteel, K. (2001). Clinical significance: History, application, and current practice. Clinical Psychology Review, 21, 421-446.

Perry, J.C., Banon, E., \& Ianni, F. (1999). Effectiveness of psychotherapy for personality disorders. American Journal of Psychiatry, 156, 1312-1321.

Pine, F. (1990). Drive, ego, object, and self. A synthesis for clinical work. New York: Basic Books.

Pine, F. (1998). Diversity and direction in psychoanalytic technique. New Haven, CT: Yale University Press.

Ploeg, H.M. van der (2000). Handleiding bij de Zelf BeoordelingsVragenlijst: Een Nederlandstalige bewerking van de Spielberger State-Trait Anxiety Invento$r y$ [Manual of the State-Trait Anxiety Inventory: A Dutch translation of the Spielberger State-Trait Anxiety Inventory]. Lisse: Swets Test Publisher.

Puschner, B., Kraft, S., \& Bauer, S. (2004). Interpersonal problems and outcome in outpatient psychotherapy: Findings from a long-term longitudinal study in Germany. Journal of Personality Assessment, 83, 223-234.

Puschner, B., Kraft, S., Kächele, H., \& Kordy, H. (2007). Course of improvement over 2 years in psychoanalytic and psychodynamic outpatient psychotherapy. Psychology and Psychotherapy, 80, 51-68. 
Raudenbush, S.W., \& Chan, W.S. (1992). Growth curve analysis in accelerated longitudinal designs. Journal of Research in Crime and Delinquency, 29, 387-411.

Reich, J. (2003). The effect of axis II disorders on the outcome of treatment of anxiety and unipolar depressive disorders: A review. Journal of Personality Disorders, 17, 387-405.

Robinson, L.A., Berman, J.S., \& Neimeyer, R.A. (1990). Psychotherapy for the treatment of depression: A comprehensive review of controlled outcome research. Psychological Bulletin, 108, 30-49.

Rudd, M.D., Rajab, M.H., Orman, D.T., Stulman, D.A., Joiner, T., \& Dixon, W. (1996). Effectiveness of an outpatient intervention targeting suicidal young adults: Preliminary results. Journal of Consulting and Clinical Psychology, 64, 179-190.

Sandell, R., Blomberg, J., \& Lazar, A. (1997). When reality doesn't fit the blueprint: Doing research on psychoanalysis and long-term psychotherapy in a public health service program. Psychotherapy Research, 7, 333-344.

Sandell, R., Blomberg, J., Lazar, A., Carlsson, J., Broberg, J., \& Schubert, J. (2000). Varieties of long-term outcome among patients in psychoanalysis and long-term psychotherapy. International Journal of Psychoanalysis, 81, 921-942.

Seligman, M.E.P. (1995). The effectiveness of psychotherapy: The Consumer Reports Study. American Psychologist, 50, 965-974.

Shea, M.T., Widiger, T.A., \& Klein, M.H. (1992). Comorbidity of personality disorders and depression: Implications for treatment. Journal of Consulting and Clinical Psychology, 60, 857-868.

Spielberger, C.D. (1983). Manual for the State-Trait Anxiety Inventory (STAI). Palo Alto, CA: Consulting Psychologists Press.

Terlidou, C., Moschonas, D., Kakitsis, P., Manthouli, M., Moschona, T., \& Tsegos, I.K. (2004). Personality changes after completion of long-term groupanalytic psychotherapy. Group Analysis, 37, 401-418.

Tingey, R.C., Lambert, M.J., Burlingame, G.M., \& Hansen, N.B. (1996). Assessing clinical significance: Proposed extensions to method. Psychotherapy Research, 6, 109-123.

Vaughan, S.C., Marshall, R.D., MacKinnon, R.A., Vaughan, R., Mellman, L., \& Roose, S.P. (2000). Can we do psychoanalytic outcome research? A feasibility study. International Journal of Psychoanalysis, 81, 513-527.

Viglione, D.J. (1999). A review of recent research addressing the utility of the Rorschach. Psychological Assessment, 11, 251-265.

Viglione, D.J., Perry, W., \& Meyer, G.J. (2003). Refinements in the Rorschach Ego Impairment Index incorporating the Human Representational Variable. Journal of Personality Assessment, 81, 149-156.

Wallerstein, R.S. (1995). The talking cures: The psychoanalyses and the psychotherapies. New Haven, CT: Yale University Press.

Weiner, I.B. (1998). Principles of Rorschach interpretation. Mahwah, NJ: Lawrence Erlbaum.

Weiner, I.B., \& Exner, J.E. (1991). Rorschach changes in long-term and shortterm psychotherapy. Journal of Personality Assessment, 56, 453-465. 
Wise, E.A. (2004). Methods for analyzing psychotherapy outcomes: A review of clinical significance, reliable change, and recommendations for future directions. Journal of Personality Assessment, 82, 50-59.

Wolf, M.H.M. de. (2002). Inleiding in de psychoanalytische psychotherapie: Ontwikkeling, psychopathologie, diagnostiek en behandelvormen [Introduction to psychoanalytic psychotherapy: Development, psychopathology, diagnostics and treatment modalities]. Bussum: Coutinho.

Zevalkink, J. \& Berghout, C.C. (2006). Expanding the evidence base for the costeffectiveness of long-term psychoanalytic treatment. Journal of the American Psychoanalytic Association, 54, 1313-1319. 